Sulpicio G. Soriano MD,* Michael L. McManus MD,* Lorna J. Sullivan RN, ${ }^{*}$ Mark A. Rockoff MD,* Peter McL. Black MD PhD, $†$ Frederick A. Burrows MD*

\title{
Cerebral blood flow velocity after mannitol infusion in children
}

briefly increases cerebrovascular resistance and thereby diminishes cerebral blood volume.

Purpose: There is conflicting evidence as to whether the effect of mannitol on brain bulk arises from haemodynamic, rheologic, or osmotic mechanisms. If mannitol alters cerebral haemodynamics by inducing vasoconstriction, this change should be reflected in cerebral blood flow velocity (CBFV) in the middle cerebral artery (MCA). The purpose of this study was to evaluate the effect of mannitol on CBFV in children.

Methods: Children scheduled for intracranial surgery were enrolled. After a loading dose of $10 \mu \mathrm{g} \cdot \mathrm{kg}^{-1}$ of fentanyl, general anaesthesia was maintained with fentanyl 13 $\left.\mu \mathrm{g} \cdot \mathrm{kg}^{-1} \cdot \mathrm{hr}^{-1}\right), 66 \%$ nitrous oxide, and isoflurane $(0.2-0.5 \%$ inspired). Mean and systolic CBFV (Vm and $V s$ ) and pulsarility index (PI) were recorded with a transcranial Doppler (TCD) directed at the MI segment of the MCA. Mannitol was administered, $1 \mathrm{gm} \cdot \mathrm{kg}^{-1}$ iv over $15 \mathrm{~min}$. The osmolality $(\mathrm{Osm})$, haematocrit $(\mathrm{Hct})$, mean arterial pressure (MAP), heart rate $(H R)$, and $T C D$ variables were recorded before and 15, 30, 45, and $60 \mathrm{~min}$ after the mannitol infusion.

Results: Mannitol infusion resulted in an increase in Osm and decrease in Hct $(P<0.05)$. Heart rate, MAP and arterial carbon dioxide tensions did not change $(P>0.05)$ during the measuring period. The $\mathrm{Vm}$ did not vary from baseline. The $\mathrm{Vs}$ and $P I$ both increased briefly $(P<0.01$ at 15 min and $P<$ 0.05 at $30 \mathrm{~min}$ ) after the mannitol, suggesting an increase in resistance distal to the $M C A$.

Conclusion: The time course of CBFV changes produced by mannitol corresponds with previous animal data concerning cerebrovascular tone. Our results suggest that mannitol

\section{Key words}

ANAESTHESIA: neurosurgical, paediatric;

BLOOD: flow, velocity, cerebral;

MEASUREMENT TECHNIQUES: Doppler ultrasound, transcranial.

From the Departments of Anesthesia* and Neurosurgery†, Children's Hospital, Harvard Medical School, Boston, MA 02115.

Address correspondence to: Dr. Sulpicio G. Soriano, Department of Anesthesia, Children's Hospital, 300

Longwood Avenue, Boston, MA 02115.

Phone: (617) 355-6457. Fax: (617) 355-7887.

e-mail soriano@al.tch.harvard.edu

Accepted for publication 21 st January, 1996.
Objectif: On ne sait trop si l'effet du mannitol sur la masse cérébrale dépend d'un mécanisme hémodynamique, rhéologique ou osmotique. Si le mannitol modifie l'hémodynamique cérébrale en induisant la vasoconstriction, ce changement devrait se refléter sur la vélocité du débit sanguin cérébral (VDSC) mesurée dans l'artère cérébrale moyenne (ACM). L'objectif de ce travail était d'évaluer chez l'enfant l'effet du mannitol sur la VDSC.

Méthodes: L'étude portait sur des enfants programmés pour une intervention intracrânienne. Après une dose de charge de $10 \mu \mathrm{g} \cdot \mathrm{kg}^{-1}$ de fentanyl, l'anesthésie a été entretenue avec du fentanyl ( $\left.3 \mu \mathrm{g} \cdot \mathrm{kg}^{-1} \cdot \mathrm{h}^{-1}\right)$, du protoxyde d'azote à $66 \%$ et de l'isoflurane (inspiré 0,2-0,5\%). La VDSC moyenne et systolique (Vm et $V s)$ et l'index pulsatile (IP) on été enregistrés grâce à un Döppler transcrânien (DTC) dirigé vers le segment MI de l'ACM. Le mannitol $\left(\mathrm{l} \mathrm{g} \cdot \mathrm{hg}^{-1}\right)$ a été administré en 15 min. L'osmolalité $(\mathrm{Osm})$, l'hèmatocrite $(\mathrm{Hct})$, la pression artérielle moyenne (PAM), la fréquence cardiaque $(F C)$ et les variables du DTC ont été enregistrés avant, et $15,30,45$ et 60 min après la perfusion de mannitol.

Résultats: La perfusion de mannitol augmente l'OSM et diminue l'Hct $(P<0,05)$. La Fc, la PAM et la pression du gaz carbonique n'ont pas changé $(P>0.05)$ pendant la période de mesure. La Vm n'a pas dévié de la ligne de base, et VS et IP ont augmenté brièvement $(P<0,01$ à 15 min et $P<0,05$ à 30 min) après le mannitol, ce qui suggère une résistance distale à l'ACM.

Conclusion: L'évolution dans le temps des changements de la VDSC produits par le mannitol correspond aux données recueillies concernant le tonus cérébrovasculaire chez l'animal. Nos résultats suggèrent que le mannitol augmente brièvement la résistance cérébrovasculaire et, en conséquence, diminue le volume sanguin cérébral.

Mannitol has been a mainstay in the reduction of brain bulk in neurosurgical patients for decades. Controversy exists, however, regarding the mechanism by which such infusions exert their benefits. While osmotic mechanisms have been presumed since the first studies of Weed and McKibben in 1919,1,2 contemporary investi- 
gations have demonstrated that mannitol administration also produces haemodilution, diminishes blood viscosity, and increases cerebral blood flow. ${ }^{3-5}$ These features, along with increases in cardiac filling pressures and output have led some investigators to suggest that the resultant autoregulatory cerebral vasoconstriction, rather than osmotic dehydration, is responsible for much of the observed reduction in brain bulk.

Haemodynamic mechanisms for the effects of mannitol infusion rest upon the assumption that cerebral vasoconstriction occurs with its intravenous administration. ${ }^{6}$ We hypothesized that this vasoconstriction should be detectable by Doppler ultrasonography and that this technology should provide a suitable means by which human data regarding this phenomenon may be obtained directly. We therefore sought to describe the changes in cerebral blood flow velocity (CBFV) in patients receiving mannitol infusions for reduction of brain bulk during neurosurgical procedures to assess whether vasoconstriction occurs.

\section{Methods}

\section{Patient population}

After approval from the Human Subjects Review Board Comnittee and informed parental consent, 10 children aged 1 to $14 \mathrm{yr}$ scheduled for intracranial surgery were studied. Exclusion criteria included evidence of intracranial hypertension or haemorrhage.

\section{Anaesthetic management}

After appropriate fasting, patients were monitored before induction with a sphygmomanometer, ECG, infrared gas monitor, precordial stethoscope, pulse oximeter and temperature probe. General anaesthesia was induced using either an inhalation technique with halothane, nitrous oxide and oxygen or an iv technique with thiopentone. Neuromuscular blockade was achieved using pancuronium $\left(0.1 \mathrm{mg} \cdot \mathrm{kg}^{-1}\right)$, the trachea was intubated and the lungs were mechanically ventilated to maintain end-tidal carbon dioxide $\left(\mathrm{ETCO}_{2}\right)$ at 25-30 mmHg. After a loading dose of fentanyl (10 $\left.\mu \mathrm{g} \cdot \mathrm{kg}^{-1}\right)$, anaesthesia was maintained with fentanyl (3 $\left.\mu \mathrm{g} \cdot \mathrm{kg}^{-1} \cdot \mathrm{hr}^{-1}\right)$, isoflurane $(0.2-0.5 \%$ inspired) and nitrous oxide and oxygen ( $2: 1$ ratio). Normothermia was maintained using a passive humidifier and warming blanket.

\section{Determination of cerebral blood flow velocity}

Cerebral blood flow velocity was measured noninvasively by transcranial Doppler ultrasonography using a Medasonics CDS (Medasonics, Fremont, CA). The transducer probe was fixed to the neurosurgical head frame and placed over the temporal window contralateral to the operative site to display flow velocity from the MI segment of the middle cerebral artery (MCA). To confirm the position of the Ml segment, the MCA signal was accompanied in every case with retrograde anterior CBFV (AI segment). A range-gated pulsed Doppler probe $\left(\right.$ area $\left.=1.5 \mathrm{~cm}^{2}\right)$ with a frequency of $2 \mathrm{MHz}$, emitting power of $100 \mathrm{~mW}$, resolution of $3 \mathrm{~cm} \cdot \mathrm{sec}^{-1}$ was used. The frequency spectrum of Doppler signals, displayed on a frequency analyzer in real time was stored and analyzed at a later date. Mean and systolic CBFV ( $\mathrm{Vm}$ and $\mathrm{Vs}$ ) and the pulsatility index (PI) were determined. The Vm, Vs, and PI were measured at end-expiration to minimize the effects of positive pressure ventilation.

The $\mathrm{Vm}$ and PI are calculated values. The $\mathrm{Vm}$ is determined by computer analysis using fast-Fourier analysis to obtain time averaged values of the spectral edge. Since the envelope of the Doppler waveform corresponds to the maximum flow velocities at the centre of the vessel, the envelope of the spectra is used to calculate the mean velocities for the last five cardiac cycles. The lowest averaged frequency values for the same cardiac cycles are considered the end diastolic velocities (Vd). The PI was calculated as: $\mathrm{PI}=\mathrm{Vs}-$ $\mathrm{Vd} / \mathrm{Vm}$.

\section{Experimental procedure}

Each patient served as his/her own control. The Vm, Vs, and PI were determined, as discussed above, after the patient's skull was fixed on the head frame. This was approximately $20 \mathrm{~min}$ after induction of anaesthesia. In order to measure the effect of mannitol on blood rheology and arterial blood gases, the carbon dioxide tension $\left(\mathrm{PaCO}_{2}\right)$ and haematocrit (Hct) were determined on a Nova Stat Profile 9 (Nova Biomedical, Waltham, MA). Osmolality (Osm) was measured on a microosomometer (Advanced Instruments, Norwood, MA). All measurements were recorded prior to the infusion of mannitol (1 $\left.\mathrm{g} \cdot \mathrm{kg}^{-1}\right)$, after completion of the mannitol infusion (15 min) and at 30, 45, and $60 \mathrm{~min}$. Surgical manipulations were avoided during this $60 \mathrm{~min}$ measurement period.

\section{Statistical analysis}

Data are reported as means \pm standard deviation (SD). In order to minimize interindividual variability of physiological responses, we compared baseline values with subsequent measurements after the administration of mannitol. Changes in Osm, Hct, MAP, HR, Vm and PI were compared with each subject's baseline value with repeated measures ANOVA and the Dunnett post-hoc test. Nonlinear regression was performed on the relative values (\% change from control) of the haematocrit and 
TABLE The effect of mannitol on physiological variables

\begin{tabular}{lcllcc}
\hline & $0 \min$ & $15 \min$ & $30 \min$ & $45 \min$ & $60 \min$ \\
\hline MAP $(\mathrm{mmHg})$ & $72 \pm 12$ & $70 \pm 12$ & $69 \pm 9$ & $73 \pm 13$ & $72 \pm 10$ \\
HR $(\mathrm{BPM})$ & $95 \pm 13$ & $94 \pm 13$ & $93 \pm 18$ & $95 \pm 17$ & $93 \pm 17$ \\
$\mathrm{PaCO}_{2}(\mathrm{mmHg})$ & $31 \pm 3.3$ & $33 \pm 5.5$ & $32 \pm 3.9$ & $30 \pm 3.8$ & $30 \pm 4.3$ \\
$\mathrm{CBFVs}\left(\mathrm{cm} \cdot \mathrm{sec}^{-1}\right)$ & $69 \pm 22$ & $79 \pm 20 \dagger$ & $76 \pm 20^{*}$ & $71 \pm 22$ & $70 \pm 18$ \\
$\mathrm{CBFVm}\left(\mathrm{cm} \cdot \mathrm{sec}^{-1}\right)$ & $45 \pm 14$ & $50 \pm 15$ & $47 \pm 14$ & $44 \pm 16$ & $50 \pm 16$ \\
PI & $0.89 \pm 0.19$ & $1.1 \pm 0.2^{*}$ & $1.0 \pm 0.19$ & $0.82 \pm 0.22$ & $0.85 \pm 0.2$ \\
\hline
\end{tabular}

Data are presented as mean \pm SD.

Mean arterial pressure $=\mathrm{MAP}$; heart rale $=\mathrm{HR}$; partial pressure of arterial carbon dioxide $=\mathrm{PaCO}_{2}$; systolic cerebral blood flow velocity $=\mathrm{CBFV}_{\mathrm{s}}$; mean cerebral blood flow velocity $=\mathrm{CBFVm}$; pulsatility index $=\mathrm{PI}$. $* P<0.05,+P<0.01$.

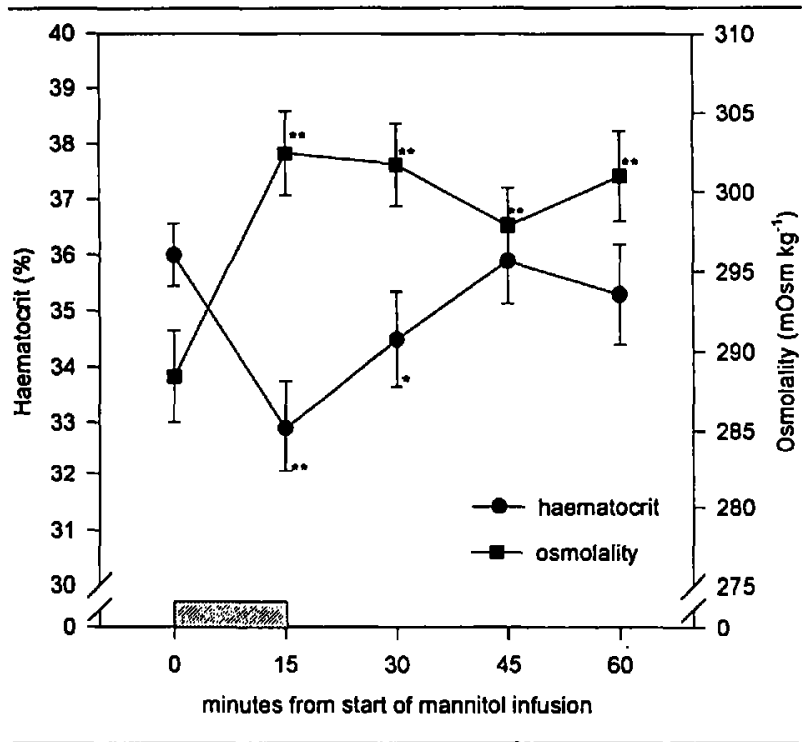

FIGURE 1 The effect of mannitol infusion (hatched bar) on plasma osmolality and hacmatocrit. (mean \pm S.D., ${ }^{* *} P<0.01$ and ${ }^{*} P<0.05$ vs baseline value).

Vs using commercially available statistics software (SigmaStat, Jandel, San Rafael, CA). Statistical significance was accepted as $P<0.05$.

\section{Results}

Ten children aged $9.0 \pm 4.2$ yr (five girls and five boys, age range: 0.8 to $14 \mathrm{yr}$ ) and weighing $33.2 \pm 19.7 \mathrm{~kg}$ were included in the study. The $\mathrm{PaCO}_{2}$ and cardiovascular variables such as HR and MAP did not change during the measuring period (Table).

Plasma Osm increased beginning at the 15 min measurement and lasting throughout the $60 \mathrm{~min}$ study period. The Hct decreased at $15 \mathrm{~min}$ and returned to baseline by $45 \mathrm{~min}$ (Figure 1 ).

The Vs and PI increased and reached maximal values 15 min after the administration of mannitol (Figure 2).
There was a trend for $\mathrm{Vm}$ to increase during the same period but this did not reach statistical significance. All variables returned to baseline values by $45 \mathrm{~min}$.

We found a high correlation between the haematocrit and Vs (Figure 3). The relationship between these variables can be expressed as $\mathrm{Vs}=1.72 e^{-0.208 \times \mathrm{Hct}}$ $(\mathrm{r}=0.608, P<0.0001)$.

\section{Discussion}

This study sought to demonstrate the CBFV correlates of a haemodynamic effect of mannitol. We observed that although Vs and PI increased after mannitol (1 $\left.\mathrm{g} \cdot \mathrm{kg}^{-1}\right), \mathrm{Vm}$ did not change. Alterations in CBFV were rapid and brief with maximal changes within $15 \mathrm{~min}$ and complete return to baseline within $45 \mathrm{~min}$. The time course of these changes closely parallels previously reported cerebral haemodynamic and arteriolar vessel diameter changes described in an animal model. ${ }^{6}$ Therefore, our data support a haemodynamic mechanism for the early effects of mannitol in humans.

Mannitol, by decreasing blood viscosity, increases $\mathrm{CBF}^{7-9}$ Haematocrit determines blood flow especially in narrow vessels. Haemodilution leads to increased blood flow by two mechanisms. Reduction in haematocrit leads to less erythrocyte aggregation and improved laminar flow. Mannitol also reduces rigidity of the erythrocyte and enhances passage through small blood vessels. ${ }^{10}$ Although the osmolality remained elevated during the 60 min study period, the haematocrit returned to control levels at $45 \mathrm{~min}$. Although other investigators have described this phenomenon, its mechanism is still unclear. ${ }^{11.12}$ We also found a high inverse correlation between the haematocrit and Vs. These mannitolinduced changes on blood rheology facilitates cerebral perfusion by reducing blood viscocity.

Direct intravital microscopy of pial vessels demonstrates vasoconstriction in response to mannitol. ${ }^{6}$ This phenomenon has also been observed during isovolaemic haemodilution with plasma. $^{7}$ Vascular beds with high 

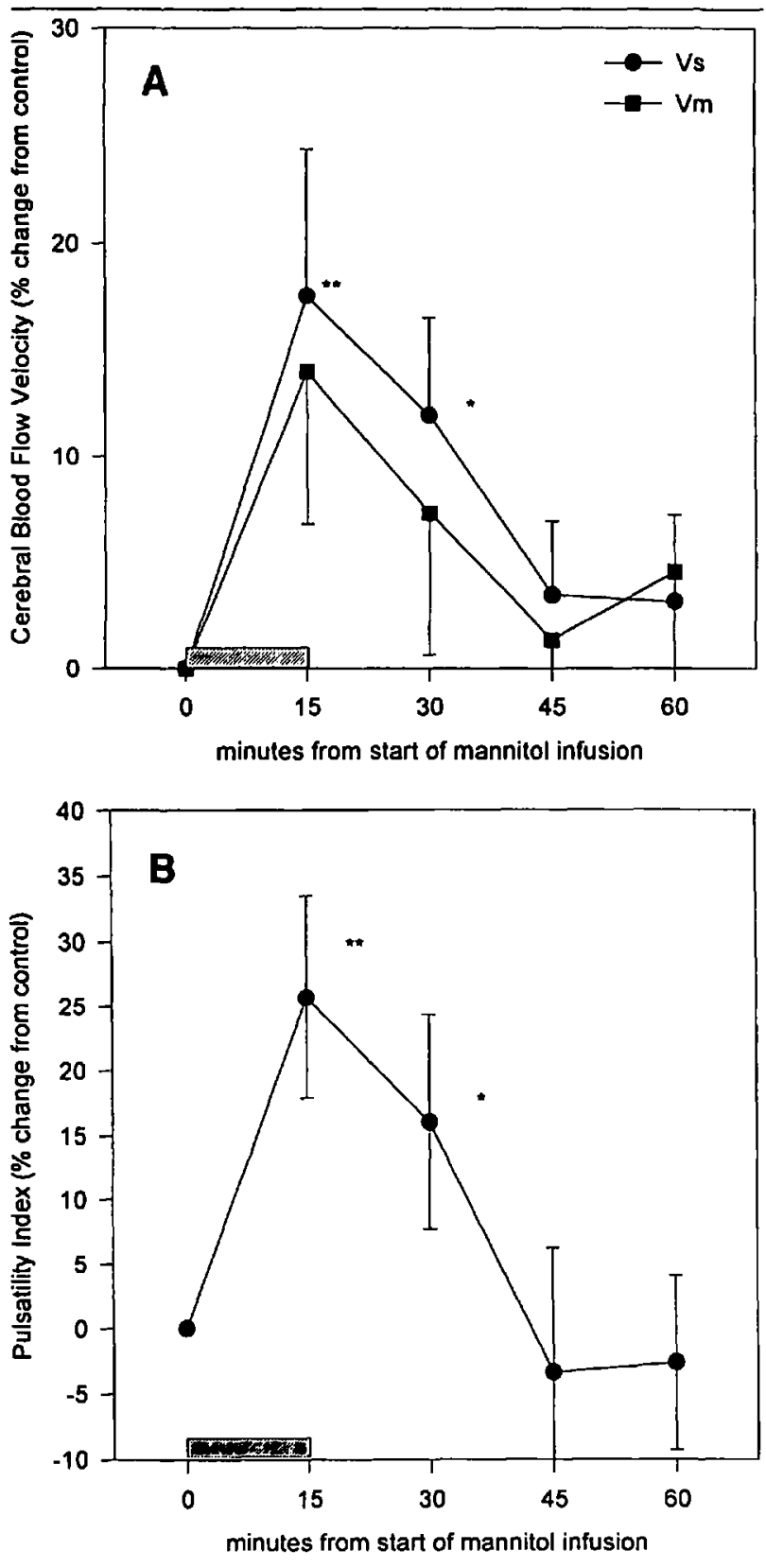

FIGURE 2 The effect of mannitol infusion (hatched bar) on (A) systolic and mean cercbral blood flow velocity ( $\mathrm{Vs}$ and $\mathrm{Vm}$ ) and (B) pulsatility index (mean \pm S.D., ${ }^{* *} P<0.01$ and $* P<0.05$ vs. baseline value).

distal resistance have high Pl. ${ }^{13}$ Proximal arteries have been shown to dilate, albeit minimally, as an autoregulatory response to increasing peripheral resistance. In our study, plasma Osm and Hct changed but the $\mathrm{Vm}$ was unchanged after the mannitol infusion. The concurrent increase in the Vs and Pl immediately after the mannitol infusion suggests that the vessels distal to the insonated artery were vasoconstricting in response to the mannitol

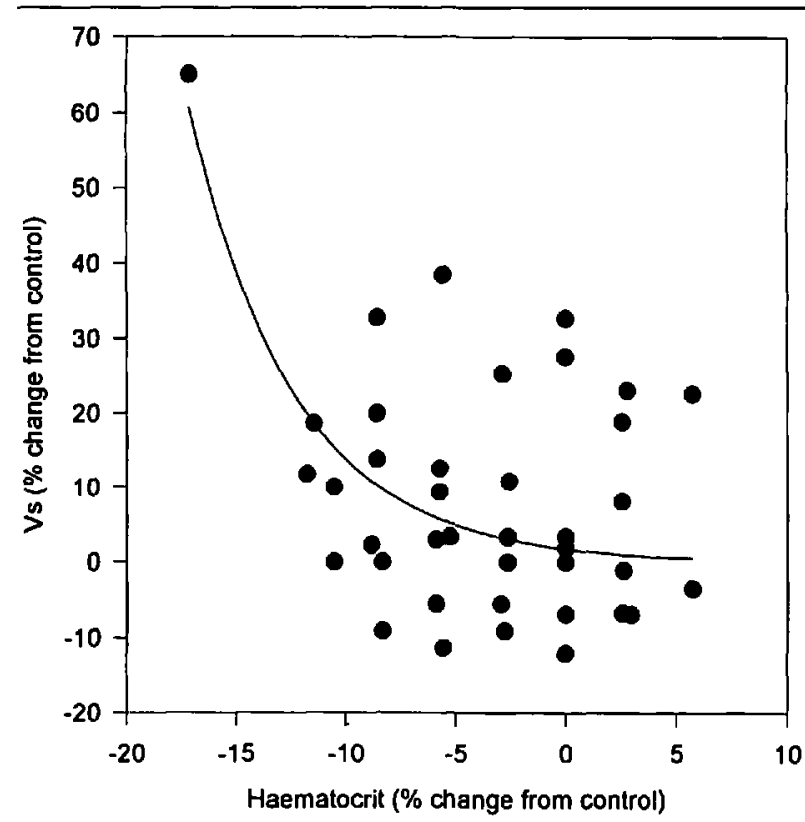

FIGURE 3 The relationship between haematocrit and Vs plotted as \% change from control. The equation for the regression curve is $\mathrm{Vs}=1.72 e^{-0.2018 \times 1 \mathrm{lct}} \mathrm{r}=0.608, P<0.0001$.

infusion. Since we controlled factors that alter $\mathrm{CBF}$ such as $\mathrm{ETCO}_{2}$, blood pressure, temperature and concentration of inhaled anaesthetic agents, the effect of mannitol either directly or indirectly (by changing the $\mathrm{Hct}$ and Osm) may account for our observed cerebral haemodynamic changes. Constriction of the pial arteries in combination with vasodilation in the proximal conducting arteries would result in the observed increase in the Vs and $\mathrm{PI}$ and stability of $\mathrm{Vm}$. We propose that the MI segment of the MCA minimally dilated in response to mannitol infusion. This phenomenon would account for the statistically insignificant rise in $\mathrm{Vm}$, and significant rise in Vs and PI. We believe that vasodilatation of the basal cerebral arteries serves as an autoregulatory response in order to maintain constant microvascular perfusion. In our study, we used TCD to measure CBFV in a single vessel, the MCA. The use of TCD as an index of cerebral perfusion depends on the ability of the $\mathrm{Vm}$ to correlate with cerebral blood flow (CBF). This, amongst other considerations, depends on the cross sectional area of the $\mathrm{Ml}$ or the precommunicating segment of the MCA remaining constant. If the diameter of the Ml segment remains constant, any change in $\mathrm{Vm}$ would reflect proportional changes in the CBF. The reproducibility of CBFV measurements with the TCD has been demonstrated in children anaesthetized with isoflurane and nitrous oxide. ${ }^{14-16}$

As expected, $V m$ increased after the infusion of man- 
nitol, but this increase did not reach statistical significance. One possible explanation for this is that the diameter of the Ml segment may not be fixed as previously thought. It has been suggested that pharmacological and autoregulatory factors can alter the diameter of the MCA. ${ }^{17}$ Nitroglycerin has been shown to reduce Vm without changing regional $\mathrm{CBF}$, suggesting that nitroglycerin causes vasodilation of basal intracranial arteries. ${ }^{18}$ Furthermore, direct measurements of the Ml segment of the MCA during changes in $\mathrm{PaCO}_{2}$ and blood pressure have revealed $2 \%$ variability in the vessel diameter in two patients with cerebrovascular disease. ${ }^{19}$ Although these findings were not clinically important, the suitability of using alterations in Vm to reflect accurately changes in CBF during such physiological changes in the $\mathrm{Ml}$ diamcter has been questioned. ${ }^{20}$ Increases in vessel diameter would increase the cross sectional area of the vessel. Since CBF is equal to the product of the cross sectional area and the $\mathrm{Vm}$, if the CBF is stable increases in the cross sectional area would decrease $\mathrm{Vm}$. The use of $\mathrm{Vm}$ as an estimate of cerebral perfusion is made on the assumption that the vessel diameter remains constant during the measuring period and vasodilatation will under estimate the true value of $\mathrm{Vm} .{ }^{17}$

In this study, CBFV was monitored for $60 \mathrm{~min}$ as a convenient observation period before surgical manipulation. Due to its invasive nature, we did not believe that it was ethical to perform direct intracranial pressure (ICP) measurements in our study. Based upon previous animal data, a 60 min observation period was chosen to allow sufficient time to begin to detect rebound effects upon the cerebral circulation and ICP. For example, Muizelaar et al. described a $20 \%$ rebound of ICP above baseline in cats $60 \mathrm{~min}$ after mannitol infusion yet only a $5 \%$ rebound of arteriolar diameter in the same period. ${ }^{6}$ Here, we observed a similar absence of rebound changes in CBFV by $60 \mathrm{~min}$ in children receiving mannitol. While small differences might be expected to remain below the threshold of detection, on the basis of these data, it remains likely that the major determinants of the rebound phenomenon are non-vascular in nature and occur beyond the observation period in this study. Potential alternative mechanisms for ICP rebound include changes in cerebrospinal fluid dynamics, alterations in blood-brain barrier osmotic gradients, and direct cellular swelling. ${ }^{6,21,22}$

In conclusion, we have described the cerebral haemodynamic effects of mannitol in children determined by transcranial Doppler sonography. The time course of changes in CBFV closely corresponds to previous animal data concerning cerebrovascular tone following mannitol infusion. Since Vs and PI peaked at the same time, we speculate that large conducting arteries dilated acutely either in direct response to changes in plasma osmolality or as part of an autoregulatory response to increased peripheral resistance. Although we did not directly investigate the vascular mechanism of this phenomenon, these findings suggest that vasoconstriction of peripheral vessels leads to a transient decrease in cerebral blood volume. This transient decrease in cerebral blood volume, can account for the reduction in brain bulk after mannitol.

\section{References}

1 Weed LH, McKibben PS. Pressure changes in the cerebrospinal fluid following intravenous injection of solutions of various concentrations. Am J Physiol 1919; 48: 512-30.

2 Weed LH, McKibben PS. Experimental alteration of brain bulk. Am J Physiol 1919; 48: 53I-55.

3 Rudehill A, Lagerkranser M, Lindquist C, Gordon E. Effects of mannitol on blood volume and central hemodynamics in patients undergoing cerebral ancurysm surgery. Ancsth Analg 1983; 62: 875-80.

4 Burke AM, Quest DO, Chein S, Cerri C. The effects of mannitol on blood viscosity. J Neurosurg 1981; 55: 550-3.

5 Donato T, Shapira Y, Artru A, Powers $K$. Effect of manniIol on cerebrospinal fluid dynamics and brain tissue edema. Ancsth Analg 1994; 78: 58-66.

6 Muizelaar JP, Wei EP, Kontos HA, Becker DP. Mannitol causes compensatory cerebral vasoconstriction and vasodilation in response to blood viscosity changes. J Ncurosurg 1983; 59: 822-8.

7 Muizelaar JP, Bouma GJ, Levasseur JE, Kontos HA. Effect of hematocrit variations on cerebral blood flow and basilar artery diameter in vivo. Am J Physiol 1992; 262: H949-54.

8 Hudak ML, Jones MD Jr, Popel AS, Koehler RC, Traystman RJ, Zeger SL. Hemodilution cause size-dependent constriction of pial arterioles in the cat. Am J Physiol 1989; 257: H9I2-7.

9 Korosue $K$, Heros $R C$. Mechanism of cercbral blood flow augmentation by hemodilution in rabbits. Stroke 1992; 23 : 1487-93.

10 Schmid-Schönbein H, Wells R. Goldstone J. Influence of deformability of human red cells upon blood viscosity. Circ Res 1969; 25: 131-43.

11 Manninen PH, Lam AM, Gelb AW, Brown SC. The effect of high-dose mannitol on serum and urine electrolytes and osmolality in neurosurgical patients. Can J Anacsth 1987; 34: 442-6.

12 Andrews RJ, Bringas $J R$, Muto RP. Effects of mannitol on cerebral blood flow, blood pressure, blood viscocity, hematocrit, sodium, and potassium. Surg Neurol 1993; 39: 218-22. 
13 Murkin JM, Lee DH. Noninvasive measurement of cerebral blood flow: techniques and limitations. Can J Anacsth 1991; 38: 805-8.

14 Pilato MA, Bissonnette B, Lerman J. Transcranial Doppler: response of cerebral blood-flow velocity to carbon dioxide in anaesthetized children. Can J Anaesth 1991; 38: 37-42.

15 Leon JE, Bissonnette B. Cerebrovascular responses to carbon dioxide in children anaesthetized with halothane and isoflurane. Can J Anaesth 1991; 38: 817-25.

16 Leon JE, Bissonnette $B$. Transcranial doppler sonography: nitrous oxide and cerebral blood flow velocity in children. Can J Anaesth 1991; 38: 974-9.

17 Schregel W, Schaefermeyer H, Sihle-Wissel M, Klein R. Transcranial Doppler sonography during isoflurane $/ \mathrm{N}_{2} \mathrm{O}$ anaesthesia and surgery: flow velocity, "vessel area" and "volume flow". Can J Anaesth 1994; 41: 607-12.

18 Dahl A, Russell D, Nyberg-Hansen R, Rootwelt $K$. Effect of nitroglycerin on cerebral circulation measured by transcranial Doppler and SPECT. Stroke 1989; 20: 1733-6.

19 Giller CA, Bowman G, Dyer H, Mootz L, Krippner W. Cerebral arterial diameters during changes in blood pressure and carbon dioxide during craniotomy. Neurosurgery 1993; 32: 737-42.

20 Kontos HA. Validity of cerebral arterial blood flow calculations from velocity measurements (Editorial). Stroke 1989; 20: 1-3.

21 Rudehill A, Gordon E, Öhman G, Linqvist C, Andersson P. Pharmacokinetics and effects of mannitol on hemodynamics, blood and cerebrospinal fluid electrolytes, and osmolality during intracranial surgery. J Neurosurg Anesthesiol 1993; 5: 4-12.

22 McManus ML, Strange K. Rebound swelling of astroglial cells exposed to hypertonic mannitol. Anesthesiology 1993; 79: A769. 